\title{
A Precarização do Trabalho dos Psicólogos Temporários no CREAS
}

\author{
Cassiele Gomes Pauli ${ }^{1}$ \\ Elisete Soares Traesel ${ }^{2}$ \\ ${ }^{1}$ Universidade Federal de Santa Maria, RS, Brasil. \\ ${ }^{2}$ Universidade Federal Fluminense, RJ, Brasil. \\ Aline Cardoso Siqueira ${ }^{1}$ \\ ${ }^{1}$ Universidade Federal de Santa Maria, RS, Brasil.
}

Resumo: O campo da Assistência Social tem admitido psicólogos que atuam em equipes interdisciplinares e enfrentam problemáticas complexas. A contratação tem sido realizada em nível municipal, de forma terceirizada e temporária. Assim, tendo como perspectiva teórica a Psicodinâmica do Trabalho, este estudo objetivou identificar as condições de trabalho, bem como seus impactos, dos psicólogos temporários que atuaram em um CREAS de um município do Rio Grande do Sul. Trata-se de uma pesquisa qualitativa de caráter transversal e exploratório, na qual participaram seis psicólogos que trabalharam em um CREAS, temporariamente, entre os anos de 2010 e 2015. Para compor a amostra, foi utilizado o procedimento chamado snowball. Os participantes responderam a uma entrevista individual semiestruturada, que foi avaliada por meio da Análise de Conteúdo. Entre os resultados, foi possível perceber que o trabalho terceirizado e temporário, para os psicólogos entrevistados, constituiu-se em uma experiência de muito investimento e desgaste. Essas condições geraram algumas frustrações e adoecimentos, devido às condições precárias de trabalho, à falta de valorização e de investimento da gestão e à insegurança quanto à renovação do contrato. Reflexões quanto à implementação dessa modalidade de contratação para psicólogos estão sendo realizadas.

Palavras-chave: Psicologia. Assistência Social. Centro de Referência Especializado da Assistência Social (CREAS). Terceirização.

\section{Precarious Work Conditions of Psychologists on CREAS}

Abstract: The field of Social Assistance has admitted psychologists who work in interdisciplinary teams and face complex problems. The hiring of psychologists has been carried out at the municipal level, outsourced and temporary. Thus, having as a theoretical perspective the Psychodynamics of work, this study aimed to identify the working conditions of temporary psychologists who worked in a CREAS, as well as their impact, in a municipality of Rio Grande do Sul. It is a qualitative research of transversal and exploratory character, in which six psychologists who worked on a CREAS, temporarily, participated between the years of 2010 and 2015. To compose the sample, the procedure called snowball was used. Participants answered a semi-structured individual interview, which was analyzed through Content Analysis. Among the results, it was possible to perceive that the outsourced and temporary work, for the psychologists interviewed, was an experience of a lot of investment, wear and tear, which generated some frustrations and illness, due to the precarious work conditions, lack of valorization and investment of the Management and insecurity regarding the renewal of the contract. Reflections on the implementation of this modality of hiring psychologists are being carried out.

Keywords: Psychology. Social assistance. Specialist Referral Center of Social Assistence (CREAS). Outsourcing. 


\title{
La Precariedad del Trabajo de los Psicólogos Temporales en el CREAS
}

\begin{abstract}
Resumen: El campo de Asistencia Social ha admitido a psicólogos que trabajan en equipos interdisciplinarios y enfrentan problemas complejos. La contratación se ha realizado a nivel municipal, subcontratada y temporal. Así, tomando la Psicodinámica del Trabajo como una perspectiva teórica, este estudio tuvo como objetivo identificar las condiciones de trabajo, así como sus impactos, de los psicólogos temporales que trabajaron en un CREAS en un municipio de Rio Grande do Sul, Esta es una investigación cualitativa de naturaleza transversal y exploratoria, en la que seis psicólogos que trabajaron en un CREAS participaron temporalmente entre $2010 \mathrm{y}$ 2015. Para componer la muestra, se utilizó el procedimiento llamado snowball. Los participantes respondieron a una entrevista individual semiestructurada, que se evaluó mediante el Análisis de Contenido. Entre los resultados, fue posible notar que el trabajo subcontratado y temporal, para los psicólogos entrevistados, constituyó una experiencia de mucha inversión y agotamiento. Estas condiciones generaron algunas frustraciones y enfermedades, debido a las precarias condiciones de trabajo, a la falta de apreciación y de inversión de la administración y a la inseguridad con respecto a la renovación del contrato. Se están realizando reflexiones sobre la implementación de este tipo de contratación para psicólogos.
\end{abstract}

Palabras clave: Psicología. Asistencia social. CREAS, Subcontratación.

\section{Introdução}

A atuação da Psicologia tem se ampliado no campo da Assistência Social nas últimas décadas, em decorrência do Sistema Único da Assistência Social (SUAS) e da implantação de políticas públicas nesse campo conforme Brasil (2005). A inserção do psicólogo nesse campo tem sido efetivada nacionalmente pelas prefeituras municipais, com contratações realizadas de acordo com a diretriz da descentralização.

Muitas são as vias de ingresso do psicólogo na Assistência Social, que podem ocorrer por meio de concursos públicos, contratos temporários, contratação pela Consolidação das Leis do Trabalho (CLT), trabalho autônomo, entre outros tipos de vínculo que direcionam o trabalho a ser desenvolvido. As atividades, a carga horária, o público e a escolha das ferramentas necessárias para a prestação dos serviços profissionais são definidos pelas diretrizes nacionais, influenciando o desenvolvimento da metodologia de trabalho.

O campo da Assistência Social é complexo, podendo ser pensado sob diversas perspectivas e áreas do conhecimento, assumindo sua faceta interdisciplinar (Yamamoto, \& Paiva, 2010). A interdisciplinaridade é aconselhada no SUAS como uma medida necessária para que o trabalho com as famílias e com as comunidades seja eficiente. Neste contexto, o psicólogo é um membro indispensável nas equipes, em virtude de que, nos processos de exclusão social, estão presentes implicações subjetivas que podem ser constatadas por esse profissional (Yamamoto, \& Paiva, 2010).

Um dos locais em que os psicólogos desenvolvem seu trabalho no SUAS é no Centro de Referência Especializado de Assistência Social (CREAS). Esse é um espaço que disponibiliza um serviço de Assistência Social de média complexidade e especializado, que acolhe as famílias e os indivíduos em situação de ameaça ou violação de direitos. Além disso, o CREAS é um lugar que visa ao fortalecimento de vínculos familiares e comunitários, priorizando a reconstrução das relações familiares quando já houve violação dos direitos. Trata-se de um serviço continuado prestado a crianças, adolescentes, jovens, adultos, idosos e mulheres, com foco em casos relacionados à violência física, psicológica e sexual, ao tráfico de pessoas, ao cumprimento de medidas socioeducativas em meio aberto, a situações de risco pessoal e social associados ao uso de drogas, entre outros (Conselho Federal de Psicologia [CFP], 2009).

No CREAS, o trabalho é realizado através da interação de inúmeros profissionais em uma perspectiva multidisciplinar, incluindo assistente social, psicólogo, advogado, entre outros especialistas, que podem ser contratados de acordo com as demandas do local, sendo um constante construir de práticas (Conselho 
Federal de Psicologia [CFP], 2009). A inserção do psicólogo na Assistência Social é recente e, por isso, sua atuação é complexa e exige uma formação profissional diferente da formação tradicionalmente oferecida pelos cursos de Psicologia no Brasil (Yamamoto, \& Paiva, 2010). Neste contexto, o psicólogo deverá enfrentar e manejar situações de adversidade de pessoas com direitos violados, ter formação adequada e específica para atuação no campo, participar de capacitações, possuir habilidade para trabalhar em grupo, em rede e de forma interdisciplinar, além de possuir expertise em diferentes campos do conhecimento. Essas atribuições parecem incompatíveis com um contrato terceirizado e temporário.

A contratação temporária faz parte de uma nova fase do desenvolvimento capitalista, marcada pela hegemonia da lógica financeira e pela condição da lógica produtiva do capital (Harvey, 1992). Esse formato de trabalho atual traz duas vertentes, uma delas é a facilidade em se adaptar às novas exigências do mercado, desobrigando a gestão de tudo o que for rígido, fixo ou estável, transferindo a responsabilidade da gestão para um terceiro - o trabalhador. Por outro lado, Antunes (2005) afirma essa transferência desresponsabiliza a empresa de cumprir com encargos relacionados aos direitos do trabalhador, diminuindo os custos de sua manutenção, fragmentando o trabalho coletivo, vulnerabilizando os trabalhadores, deixando-os invisíveis. O autor observa que o capitalismo reduz as necessidades do ser social que trabalha, na medida em que transforma o trabalho humano em algo estranho a ele mesmo, distanciando a subjetividade do sujeito do seu trabalho.

Segundo Druck e Franco (2007), as novas formas de trabalho existentes na atualidade promovem mudanças inspiradas no toyotismo, que tem na terceirização uma de suas principais práticas, visando a ganhos de produtividade, à redução de custos e à racionalização do uso da força de trabalho. Job (2003) relata que a terceirização, a quarteirização e os contratos temporários crescem cada vez mais em busca da flexibilização no uso do trabalho. Novas características foram incorporadas à função: qualificação e polifuncionalidade, visão sistêmica, rotação das tarefas e flexibilização do trabalho que está sendo desenvolvido, cada vez mais, em todos os segmentos. Segundo Sennet (2001), é natural que a dita flexibilidade cause insegurança, pois as pessoas, muitas vezes, não sabem quais caminhos devem seguir.
Essa forma de organização de trabalho acabou refletindo no campo da Assistência Social. Para Macedo e Dimenstein (2011), a implantação do SUAS e sua rápida expansão, apesar de representarem significativa ampliação do mercado de trabalho para os psicólogos e outros profissionais no setor, contraditoriamente, aprofundaram a precarização das relações de trabalho nas políticas públicas. Já para Grossi et al. (2013), a Assistência Social apresenta intensa introdução de formas de contratação terceirizada, redução da carga horária para diminuir salários, alto nível de rotatividade, insegurança no trabalho e inúmeros vínculos empregatícios.

A terceirização implica conviver com a insegurança quanto ao emprego, às precárias formas de contratação e os baixos salários, além da falta de perspectivas profissionais futuras, como ascensão na carreira e ausência de qualificação/capacitação profissional (Raichelis, 2010). No campo das políticas de Assistência Social, o estudo de Macedo e Dimenstein (2011) encontrou $37,6 \%$ dos psicólogos em contratos temporários.

A precarização das condições de trabalho na Assistência Social interfere na qualidade do vínculo estabelecido com os usuários e suas famílias, uma vez que os profissionais são chamados a intervir em múltiplas demandas, não conseguindo apreender a imensidão que se encontra nas entrelinhas de cada situação de violência (Antunes, 2005). A rotatividade excessiva de profissionais, a descontinuidade das ações, a fragilidade do trabalho das equipes e a despotencialização dos trabalhadores da Assistência Social também fazem parte dos resultados do SUAS (Macedo et al., 2011). O desamparo e a precariedade do trabalho manifestam-se das mais variadas formas para os trabalhadores, como, por exemplo, através do adoecimento, podendo também aparecer por meio do absenteísmo e pelo presenteísmo. Para o Estado, esses problemas se refletem no aumento de concessão de benefícios previdenciários e acidentários (Amaral, Mota, \& Alves, 2011).

Cabe destacar que, para Dejours (1999), a vivência do trabalhador estará permeada pelas características do trabalho, pelo jogo de forças estabelecido e pelo reconhecimento, sendo a Psicodinâmica do Trabalho um referencial teórico que possibilita analisar a dinâmica dos contextos laborais. Mendes (2007) complementa que essa dinâmica ocorre por meio das mais variadas forças, que podem ser visíveis ou não, capazes de influenciar esse contexto e impactar o trabalhador. 
A análise da dinâmica dos contextos laborais torna-se possível porque a Psicodinâmica do Trabalho estuda a relação prazer/sofrimento como um fator entrelaçado que constitui o cerne da mobilização subjetiva no trabalho. A dinâmica dessa relação coloca o trabalhador entre a normalidade e a patologia, tendo em vista que o sofrimento pode ser transformado, encontrando o caminho da resistência e deflagrando uma ação frente ao real. Sendo assim, para Ferreira, Araújo, Almeida e Mendes (2011), esta condição de sofrimento quando compreendida pelo profissional pode torná-lo criativo e potencializar sua saúde. Entretanto, frequentemente, a possibilidade de criação é bloqueada, dando lugar às estratégias defensivas, que constituem tentativas ineficazes de suportar a realidade que permanece dolorosa. Desta forma, o trabalho é relegado ao vazio e à repetição, obstruindo a mudança, a realização, o reconhecimento e a consolidação da construção da identidade no registro social do trabalho.

Considerando os elementos apontados, Merlo e Mendes (2009) entendem que a compreensão da vivência subjetiva dos trabalhadores na ótica da Psicodinâmica do Trabalho concentra-se nas manifestações do sofrimento no trabalho, ou seja, em sua dimensão subjetiva, recolhida através do relato dos sujeitos sobre suas vivências no trabalho e sobre sua própria atividade. Esse sofrimento é inerente ao encontro com o trabalho, sendo uma experiência afetiva que não é necessariamente negativa. Ao contrário, é o instrumento que impulsiona o trabalhador em busca de uma solução que lhe permitirá superar a própria dor. Entende-se, então, que o sofrimento vivenciado no trabalho pode tornar-se um motor para a realização e o prazer desde que haja o reconhecimento do fazer que é repatriado para o registro da identidade, concedendo sentido ao trabalho. Nessa direção, um dos principais méritos da Psicodinâmica do Trabalho é o de possibilitar o desvelamento dos aspectos psicodinâmicos da organização de trabalho e compreender as contradições e agressões à saúde mental antes da instalação de agravos, permitindo a atuação em um nível infrapatológico e a colocação em ação de estratégias de enfrentamento pelo coletivo de trabalhadores, constituindo, assim, uma intervenção preventiva (Merlo \& Mendes, 2009).

Dejours (2004) afirma que o significado do trabalho é próprio e singular para cada sujeito, constituindo-o. O trabalho proporciona um foco relevante para a organização da personalidade e, com isso, a carreira é de extrema relevância na vida do sujeito, pois atravessa também aspectos de sua vida pessoal e social. Essa importância reflete diretamente na percepção que o sujeito tem de si mesmo e de sua vida.

As pessoas obtêm satisfação na vida e no trabalho na medida em que conseguem realizar atividades que permitam uma adequada manifestação de suas habilidades, necessidades, valores, interesses, traços de personalidade e concepções sobre si mesmo (Super, 1990). Para Ramos et al. (2010), o trabalho está no centro da sociedade, pois pode ser considerado o principal organizador do modo de vida dos sujeitos e, por isso, a inserção profissional é tão importante. Outrossim, o trabalho faz parte da constituição da identidade do sujeito, ou seja, a inserção no mercado de trabalho permite que o trabalhador tome consciência de si, de suas necessidades, vocação e escolhas. A violência advinda dos modos de dominação contemporâneos gera servidão às demandas de produtividade, além de lucro e resultados, levando à intensificação do trabalho. Nesse contexto, assiste-se a uma derrocada dos acordos éticos do trabalho e a uma erosão do tecido social do trabalho. Na perspectiva dejouriana, esses modos de gestão manifestam um desrespeito pelo trabalho humano, substituindo-o sem a devida consideração. $\mathrm{O}$ autor defende que trabalhar é muito mais do que produzir bens e serviços, pois o trabalho tem o poder de mobilizar a personalidade e a inteligência em sua totalidade (Dejours, 2011).

Os processos gerenciais atuais têm desconsiderado a subjetividade no trabalho, avaliando apenas seus resultados. Entretanto, o exercício profissional inclui gestos, saber-fazer, engajamento do corpo, mobilização do pensamento. Está diretamente ligado, em sua essência, ao processo de transformação de si mesmo. Assim, a relação entre trabalho e subjetividade é inegável e não pode cair na invisibilidade, sob pena de levar a uma anulação do sujeito, reduzindo-o a um mero objeto ou recurso, relegado à subserviência e à obediência. "O trabalho sempre coloca à prova a subjetividade, da qual esta última sai acrescentada, enaltecida, ou ao contrário, diminuída, mortificada. Trabalhar constitui para a subjetividade, uma provação que a transforma" (Dejours, 2004, p. 30).

Na visão de Dejours (1994, 1999), o sujeito busca manter um equilíbrio em relação ao trabalho. Esse equilíbrio seria o resultado de uma regulação que requer estratégias defensivas especiais, elaboradas pelos próprios trabalhadores. O autor afirma que a 
normalidade é considerada um enigma na nova dinâmica da Psicopatologia do Trabalho, pois a maioria dos trabalhadores não consegue preservar um equilíbrio psíquico e manter-se na normalidade. A exceção passou a ser a regra, ou seja, a regra hoje é o sofrimento e não a normalidade. Nesse sentido, muitas vezes, o trabalho acaba se associando mais à ideia de sofrimento do que a de satisfação. Por esse motivo, Codo, Sampaio e Hitomi (1993) ressaltam que as pessoas acabam rompendo o conceito afeto/trabalho, tornando o afeto restrito ao lar e à família, deixando a relação afetuosa com o trabalho à margem, tornando-o desafetivo e insuportável.

Outrossim, Chiavenato (2002) destaca que os enfraquecimentos das identidades ocupacionais e de classe resultam em uma maior individualidade do sujeito, além de um afastamento dos demais em uma trajetória bastante particular da empregabilidade e histórico de carreira na busca de conquistas e manutenção do emprego. As tarefas repetitivas, assim como as de risco que geram medos específicos, fazem os trabalhadores desenvolverem estratégias defensivas, para que o sofrimento não seja imediatamente identificável e fique mascarado ou disfarçado por um tempo. Para Dejours (2004), essa estratégia defensiva é a maneira que gera menor sofrimento ao trabalhador e $o$ ajuda a se manter nesse ambiente, mas, certamente, em algum momento ou de alguma forma, esse conteúdo latente irá se manifestar.

Diante dos estudos sobre o impacto da terceirização e da reflexão feita a partir do arcabouço teórico da Psicodinâmica do Trabalho, é possível entender a complexidade da adoção da terceirização para trabalhadores que realizam atendimento de situações de maus tratos, problemáticas familiares graves e fatores de riscos individuais e sociais. Assim, este estudo objetivou identificar as condições de trabalho, bem como seus impactos, dos psicólogos temporários que atuaram em um CREAS de um município do Rio Grande do Sul.

\section{Método}

\section{Delineamento e participantes}

Trata-se de um estudo qualitativo, descritivo e transversal, cujo interesse está na compreensão particular do fenômeno estudado, sem visar a generalizações (Martins \& Bicudo, 1994). Participaram deste estudo seis psicólogos, de ambos os sexos, que atuaram em um CREAS de uma cidade do Rio Grande do Sul, com idades entre 29 e 43 anos. O tempo de atuação variou de um ano e cinco meses a cinco anos, na maioria dos casos com períodos de recesso entre um contrato e outro. Os critérios de inclusão consistiram em: ser psicólogo, ter tido contratação temporária em um CREAS entre os anos de 2010 e 2015, com término do contrato até o ano de 2015, com pelo menos 6 meses de atuação. Esta pesquisa não apresenta nenhum critério de exclusão.

\section{Instrumentos}

Foi realizada uma entrevista semiestruturada, desenvolvida para esse projeto, com os participantes do estudo, tendo como abordagem teórica a Psicodinâmica do Trabalho (Dejours,1999). Esse enfoque tem sido muito utilizado por pesquisadores brasileiros, cuja proposta investigativa busca gerar novos conhecimentos, revelando-se um instrumento para intervenção, prevenção e transformação de processos de trabalho agressivos à saúde psíquica (Merlo, \& Mendes, 2009). O roteiro de entrevista contou com questões sobre a prática profissional dos psicólogos, a saber: o período de permanência no serviço; os aspectos negativos e positivos da contratação temporária; as condições no ambiente de trabalho desses profissionais; a estrutura física e o clima de trabalho; a experiência do trabalho temporário e seus pontos positivos e negativos, entre outras questões. A Psicodinâmica do Trabalho contribuiu no sentido de possibilitar compreender as vivências subjetivas dos trabalhadores e sua relação com o trabalho por meio da relação prazer/sofrimento, as estratégias defensivas desenvolvidas pelos trabalhadores e também o reconhecimento alcançado.

\section{Procedimentos e considerações éticas}

Este projeto de pesquisa foi submetido e aprovado pelo Comitê de Ética em Pesquisa com Seres Humanos da universidade sede da pesquisa (CAAE $\mathrm{n}^{\circ}$ 61830216.0.0000.5346). A amostra foi por conveniência, a partir da indicação dos psicólogos que tiveram contrato temporário entre os anos de 2010 e 2015 e do procedimento chamado "bola de neve", permitindo que os participantes iniciais do estudo pudessem indicar novos participantes que, por sua vez, indicaram outros e assim sucessivamente, até que fosse 
alcançado o "ponto de saturação". Fontanella, Ricas e Turato (2008) e World Health Association - WHO (1994) ensinam que a saturação é atingida quando os novos entrevistados passam a repetir os conteúdos já obtidos em entrevistas anteriores, sem acrescentar novas informações relevantes à pesquisa. Uma vez feita a indicação, foi realizado um convite para apresentar os objetivos e os procedimentos da pesquisa, além dos aspectos éticos. Os participantes assinaram o Termo de Consentimento Livre e Esclarecido (TCLE), em duas vias, sendo que uma delas foi entregue ao profissional. O TCLE contém as informações sobre o estudo, assim como o contato das pesquisadoras e do Comitê de Ética da instituição de ensino superior sede da pesquisa. Sublinha-se que a participação dos psicólogos foi voluntária, sigilosa e anônima. Eles puderam solicitar esclarecimentos sobre os procedimentos e outros assuntos relacionados com a pesquisa, podendo interromper sua participação a qualquer momento, sem que isto lhe trouxesse prejuízo. As entrevistas foram realizadas na residência dos participantes ou no Departamento de Psicologia da universidade sede do estudo e teve duração mínima de 40 minutos e máxima de 1 hora e 30 minutos, tendo sido gravadas e transcritas para análise.

\section{Análise de dados}

Os achados foram avaliados com base na Análise de Conteúdo (Bardin, 2009). Este procedimento de análise consiste em um conjunto de técnicas de investigação das comunicações, cujo emprego se dá por meio do uso de métodos sistemáticos e escopos de descrição do conteúdo das mensagens obtidas. Foram construídas a posteriori três categorias temáticas: (1) Mínimo para trabalhar; (2) Rotatividade dos profissionais; e (3) Gestão política ineficiente.

\section{Resultados e discussão}

Os participantes elucidaram as diversas formas de precarização que encontraram em seus percursos, trazendo à tona as dificuldades do trabalho temporário em um serviço de suma importância, porém, pouco assistido pelos gestores. Podemos observar os achados através das categorias descritas abaixo.

\section{O mínimo para trabalhar}

Essa categoria incluiu as falas dos profissionais quanto às condições físicas de trabalho vivencia- das cotidianamente no CREAS. Considerando que a infraestrutura de trabalho é fundamental para que as atividades sejam desenvolvidas, o relato dos psicólogos que atuaram no CREAS retrata problemas nessas condições, conforme as falas do Participante 6: "espaço físico, ele não era dos melhores, a gente tinha o mínimo, as mínimas condições de trabalho”; e do Participante 2: "às vezes, precisava de carro, não conseguia carro. O espaço físico, nós 'tinha' só duas 'sala' pra atendimento, nós éramos entre cinco psicólogos". É possível verificar esta condição também no relato do Participante 3:

Lá no prédio antigo que a gente "tava", era muito ruim né?! Chovia dentro, era sei lá... Era uma época que chovia bastante, tinha toda a fiação, chovia nas salas e a gente tinha muito medo né?! Que acontecesse algo ali, era muito perigoso! Os computadores molhavam todos. Então, o clima era um clima bem estressante assim né?! Ah! A gente não conseguia trabalhar vários dias (Participante 3).

Da mesma forma, o Participante 1 traz mais detalhes sobre esta situação: "a equipe se organizava e tinha todo um cronograma de questões importantes, mas não tinha carro, né?! Tinham coisas que faziam muita falta, por exemplo, estragava uma impressora, vai se passando o tempo". Por fim, o Participante 4 expõe as questões relacionados à limpeza do local de trabalho:

A estrutura física... Não tínhamos acompanhamento, até o papel higiênico a gente comprava. A limpeza do CREAS, por um bom tempo, a gente fechava tipo uma horinha mais cedo e a gente ficava uma horinha, duas a mais pra limpar! A gente só encostava a porta pra não verem que a gente 'tava' faxinando o local (Participante 4).

O relato dos participantes evidencia que eles conviviam diariamente com a falta de todos os tipos de recursos, como: infraestrutura inapropriada, que trazia riscos aos trabalhadores e usuários; falta de espaço físico para realizar os atendimentos; dificuldades em realizar as visitas domiciliares, devido ao compartilhamento do automóvel disponibilizado com os outros serviços da Assistência Social; falta de materiais de trabalho; interferência do clima nas condições físicas precárias do prédio; entre outras necessidades que o serviço apresentava em sua rotina de trabalho. 
Além disso, realizar a limpeza do ambiente de trabalho pode ser considerado uma evidência de desvalorização do profissional por parte da gestão, impactando de forma negativa a subjetividade desse trabalhador.

De acordo com a Psicodinâmica do Trabalho, as condições de trabalho podem ocasionar vivências de sofrimento caso exista indisponibilidade de recursos materiais e humanos (Mendes, \& Marrone, 2011), sendo essa uma realidade nos serviços de Assistência Social no Brasil (Paz, 2015). Seligmann (2011) assevera que, em contextos de trabalho altamente precarizados como os expostos, há uma vulnerabilidade maior ao adoecimento, pois a exposição contínua a situações humilhantes e desgastantes culmina com o esgotamento. Com isso, o trabalhador fica extremamente sujeito a agravos à sua saúde mental, sendo que a escassez no mercado de trabalho e as limitadas alternativas institucionais de proteção reproduzem e alimentam esses processos de fragilização. À luz ainda da Psicodinâmica do Trabalho, pode-se afirmar que a relação dos psicólogos participantes desta pesquisa com seu trabalho é geradora de dor e sofrimento específicos e intransponíveis, impossibilitando o confronto com o real e a ação transformadora do sujeito. Assim, pode-se inferir que esses trabalhadores deveriam estar usando defesas para se manter em um estado de normalidade, escondendo-se para submeter-se a demandas humilhantes, tomando atitudes de racionalização dos problemas e não realizando o enfrentamento de suas causas reais. Essas estratégias defensivas obstaculizam a mudança, a capacidade de realização e a retribuição simbólica, impedindo a consolidação da identidade no trabalho.

Além das dificuldades de infraestrutura, pode-se notar um processo de responsabilização da gestão para com o trabalhador quando ela exige da equipe "adaptar-se" à falta e construir novas metodologias de trabalho. Um exemplo desse aspecto é notado na fala da Participante 2: "e a gestão sempre nos colocando que nós tínhamos que criar metodologias, né?! Pra... pra absorver isso. Então, a equipe 'tava' toda sempre sob pressão e eu acho que essa pressão acabava prejudicando, né?... o desenvolvimento do trabalho". Essa postura pode causar desconforto e mal-estar no ambiente, levando a um processo de alienação. O que vai ao encontro das ideias de Ferreira e Mendes (2003), que defendem que as condições de trabalho são formadas pelos elementos presentes no local de trabalho e caracterizam sua infraestrutura, apoio e práticas administrativas (Ferreira, \& Mendes, 2003).

A demonstração de pouco investimento no serviço e do não atendimento às necessidades mínimas dos profissionais podem desencadear sofrimento, identificado através de medo, insatisfação, insegurança, estranhamento, desorientação, impotência diante das incertezas, alienação, vulnerabilidade, frustração, inquietação, angústia, depressão, tristeza, agressividade, impotência para promover mudança, desgaste, desestímulo, desânimo, sentimento de impotência, desgaste físico, emocional, desvalorização, culpa, tensão e raiva. Estudos no campo da Assistência Social corroboram esses resultados. Ximenes, Paula e Barros (2009) afirmam que os psicólogos que atuam na Assistência Social são expostos à oferta de condições de trabalho precárias. Essas vão desde a fragilidade de vínculos empregatícios até as situações de precariedade das instalações físicas e dos equipamentos necessários e a ocorrência de possíveis deturpações na prática do profissional, devido à vulnerabilidade em que se encontram.

\section{Rotatividade dos profissionais}

Essa categoria incluiu dados sobre a instabilidade sentida no ofício refletida na alta rotatividade dos funcionários temporários e terceirizados. Foram características marcantes das entrevistas com os psicólogos a quebra destes contratos temporários e a falta de continuidade do trabalho, tornando as atividades laborais fragmentadas, conforme segue: "eu acho que isso prejudica muito, tanto o serviço quanto o profissional, porque o profissional também acaba se desgastando, preocupado se vai ter ou se não vai ter emprego. Então, eu acho o contrato temporário uma coisa bem negativa" (Participante 6).

A fala ilustra que a rotatividade no CREAS abrange tanto a equipe quanto a gestão do serviço, gerando um desconforto relacionado à falta de continuidade das ações trabalhadas. O crescente número de profissionais temporários tornava as relações frágeis no dia a dia, devido ao tempo em que permaneciam no local, pois, assim que os psicólogos criavam um vínculo, já estava próximo do encerramento dos contratos. Segundo Stancato e Zilli (2010), a rotatividade é o conceito usado para representar a flutuação de pessoas em uma organização/instituição, é o movimento de entrada e saída de profissionais em postos de trabalho e, se a rotatividade for excessiva, pode gerar 
instabilidade e descontinuidade. Já para Paz (2015), o receio pela perda do emprego devido às instabilidades econômicas e sociais torna os processos de trabalho mais sofridos, assustando os que permanecem empregados. Conforme Dejours (2001), trata-se de uma naturalização da prática social injusta, vivenciada pelas pessoas como um mal dos tempos modernos, uma consequência, quase como um destino. De acordo com o autor, a banalização do mal no mundo do trabalho não é algo inédito. A novidade reside no fato de que isso seja considerado bom e justo. Estes laços perversos reproduzidos pela lógica de um sistema que alimenta insensivelmente as injustiças "são capazes de aplacar a consciência moral diante do sofrimento assistido, dando origem à tolerância ao mal" (Merlo, Traesel, \& Baierle, 2013, p.72). Na perspectiva dejouriana, o individualismo e o isolamento presentes nos relatos constituem uma grande perda para a saúde, pois trabalhar é também viver junto. $\mathrm{O}$ autor defende que os trabalhadores não são observadores de um mundo perverso que os reduz a sujeitos passivos: "são capazes de se proteger, de encontrar uma saída, possuem capacidade de emancipação, de reapropriação, de transformação e reconstrução da realidade" (Dejours, 2011, p. 43). Assim, os círculos de dominação vivenciados pelos participantes somente poderiam ser quebrados pelas vias da interlocução e da cooperação.

Nesse estudo, a maioria dos psicólogos tinha, pelo menos, mais um emprego em concomitância ao trabalho no CREAS. Essa necessidade se dava em decorrência da instabilidade contratual e das más condições de trabalho, fatores já apresentados. A necessidade de realizar jornadas duplas trazia mais desgaste ao trabalhador, contudo constituía-se em maior seguridade. Segundo Paz (2015), como garantia de sobrevivência, muitos profissionais da Assistência Social precisam trabalhar em outras atividades ou até mesmo em municípios limítrofes, em decorrência dos baixos salários pagos e da instabilidade em relação à manutenção do emprego, herdados pelas contratações temporárias.

A rotatividade identificada foi associada a uma descontinuidade do trabalho pelos psicólogos, cujo principal prejudicado era o usuário. Muitas vezes, não havia a interação entre o profissional antigo com o novo, impactando o trabalho. Segundo os participantes, "chegava lá no final do contrato e a gente já começava: o que faremos com os nossos pacientes? Quem vai assumir? Vamos ficar? Não vamos ficar? O que será dos nossos pacientes, né?" (Participante 6); "vamos dizer assim, um pouco frustrante, porque, às vezes, tu não 'consegue' dar continuidade, tu não 'consegue' né?! Acompanhar essa complexidade ou enfim... ver todos os desdobramentos que eles vão ter, né?" (Participante 5). Conforme esses relatos, a rotatividade tornava as atividades no CREAS descontinuadas, já que cada nova equipe iniciava o trabalho através do seu olhar, sem ter conhecimento do que tinha sido desenvolvido pela equipe anterior. Paz (2015) traz que a rotatividade influencia a falta de continuidade dos atendimentos, provocando um rompimento, fazendo com que os usuários desconfiem da efetividade do serviço e das ações públicas. Em um estudo realizado por Freire e Alberto (2013), a rotatividade ganhou destaque como um fator que afeta a formação do profissional e o vínculo com o trabalho. A ausência de concursos públicos para os profissionais na política de assistência, especialmente no CREAS, tem gerado um ciclo de contratações temporárias, não havendo uma perspectiva de mudança nessa cultura do serviço, perdendo, com isso, muitas particularidades a cada troca de equipe (Conselho Federal de Psicologia [CFP], 2010; Ribeiro, \& Guzzo, 2014; Yamamoto, \& Paiva, 2010). Mesmo que autores como Chiavenato (2006) afirmem que a renovação advinda da rotatividade possa revigorar a equipe e trazer novas ideias à instituição, o que se observou nesse equipamento social foi a constituição de uma equipe predominantemente temporária e altamente rotativa, evidenciando a precarização presente nesse ambiente.

Pode-se inferir pelos relatos que as imposições sofridas pelos profissionais participantes exigiram renúncia a valores e princípios éticos que orientavam sua atuação profissional. Esse término brusco de contrato impedia uma atuação adequada, gerando um sofrimento específico que a Psicodinâmica do Trabalho denominou de sofrimento ético (Dejours, 1998). Esse sofrimento advém do extremo desconforto associado à execução de ordens e ações com as quais o trabalhador não concorda. Colocar-se a serviço de um sistema e ser conivente com suas injustiças coloca o trabalhador em um dilema ético insolúvel e conflitante, fazendo com que ele entre em contradição consigo mesmo, perdendo o respeito por si próprio, o que culmina com profundos abalos à sua saúde psíquica. Ainda é possível salientar a força desse coletivo, que internalizou a ideia de fracasso e impotência que lhe 
foi imposta e engendrada por um sistema que tem por objetivo enfraquecer todos os atores sociais que podem promover uma nova consciência de direitos e de cidadania.

\section{Gestão política ineficiente}

Essa categoria apresenta dados sobre a gestão do serviço e demonstra, por inúmeros aspectos, o quanto a gestão era ineficiente e geradora de doença nos seus trabalhadores. Essa gestão estava desconectada das diretrizes que norteiam o trabalho, não fornecia condições suficientes para a realização das atividades laborais, apresentava infraestrutura precária e os pacientes eram atendidos de acordo com as possibilidades do serviço, consequentemente. As falas a seguir apresentam evidências dessas afirmações: "eu vejo uma má gestão do CREAS. Hoje, é um serviço que deixa toda a sociedade muito preocupada, porque os pacientes hoje, eles estão desassistidos pelo município" (Participante 5); "a gestão! A instituição, que hoje não é gestão do município [referindo-se à terceirização], hoje os gestores são de outras instituições e eles não têm aquele contato com a Secretaria de Assistência. Então, é difícil, bem difícil!" (Participante 6). O termo gestão abrange uma série de ações como: planejar, dirigir, administrar, orientar e controlar alguma coisa, seja no âmbito pessoal e familiar, seja na esfera organizacional, tanto no setor público quanto no privado (Chiavenato, 2006). Já Dejours (1992) afirma que a organização do trabalho é responsável pelas consequências negativas ou positivas para o funcionamento psíquico do trabalhador. O contexto socioprofissional pode gerar prazer e/ou sofrimento no trabalho, influenciando a estrutura da personalidade do trabalhador. Para o autor, em algumas ocasiões, tal como a da presente pesquisa, ocorre um choque entre a história do trabalhador e a organização do trabalho. Esse descompasso acontece quando a rigidez dos modos organizacionais paralisa o profissional e este já não consegue ativar sua singularidade. Merlo et al. (2013) observam que, nessas situações, o trabalho cai no vazio e perde o sentido, pois as demandas psicológicas do sujeito são profundamente desconsideradas, constituindo-se em uma forma dolorosa de violência psicológica altamente destruidora do ponto de vista psíquico.

Evidenciou-se que os gestores falharam na garantia das condições de trabalho, e consequentemente, fracassaram na constituição da política social, sendo uma posição que vivencia instabilidade também. É possível verificar isso no relato do Participante 2: "como até os gestores são passageiros, então nunca se sabia qual a posição que ele poderia tomar diante [...] da cobrança de um profissional". Para que uma política pública aconteça, Di Giovanni (2009) analisa que é essencial que os gestores deem suporte aos profissionais, através de investimentos e relacionamentos efetivos voltados para este propósito. Em relação ao SUAS, Freire e Alberto (2013) expõem que as dificuldades e as limitações são notáveis tanto na estrutura material quanto na simbólica, tornando-se um aspecto preocupante para o funcionamento dessa política no processo de efetivação dos direitos. A prestação dos serviços no âmbito do SUAS demanda, além do conhecimento teórico, técnico e direcionamento ético-político dos profissionais, condições materiais para sua realização. Esse amparo deve ser suportado pela gestão municipal. Segundo Raichelis (2010), para que o fortalecimento do trabalho nas políticas públicas aconteça, é necessária uma gestão eficiente e participativa, que legitime os direitos dos trabalhadores e dos usuários.

Todos os entrevistados afirmaram que pelo menos um psicólogo era concursado na equipe do CREAS, considerando os cinco profissionais no período em que eles estavam em atuação, causando desequilíbrio no que tange ao direito constitucional da isonomia. $\mathrm{O}$ que se evidenciou foi a adoção de uma modalidade de trabalho temporária e, por isso, provisória, despreocupada com a formação e o perfil da equipe e com as condições de trabalho, sendo tomada como permanente, fazendo com que o serviço não se consolidasse e os trabalhadores não se fortalecessem. A repercussão da terceirização no ambiente de trabalho aumenta a incerteza e a precariedade dos postos de trabalho (Paixão \& Lorenço, 2014).

\section{Considerações finais}

O tema da presente pesquisa mostrou-se contemporâneo e pertinente devido às transformações significativas ocorridas na sociedade brasileira em 2017, que impactam cada vez mais o dia a dia do trabalhador, interferindo no processo de formação de sua identidade. A Assistência Social está amparada por políticas públicas e diretrizes de extrema relevância para atender as demandas da população e possibilitar a transformação social através do rompimento de ciclos de violência e fragilidade que se repetem por muitas gerações. 
Os profissionais que atuam no CREAS são contratados para desenvolver ações de proteção social para aqueles que se encontram em situação de vulnerabilidade, desemprego, subemprego ou com vínculos laborais precarizados. Apesar disso, muitos desses profissionais, que deveriam atuar de forma continuada e permanente, operam em um contexto em que não possuem seus direitos assegurados.

Um fator importante a ser pensado está relacionado ao número significativo de profissionais com contratação temporária (terceirizados) versus o número reduzido de profissionais concursados, o que remete à cultura da terceirização e da descontinuidade do serviço. Essa falta de investimento e/ou planejamento em relação à equipe do CREAS segue fazendo parte da trajetória desses profissionais, sendo que, em nenhum momento, houve suporte da gestão em relação à continuidade ou ao rompimento do trabalho dos psicólogos, menos ainda uma orientação em relação ao planejamento de carreira desses profissionais.

Além disso, no que se refere à equipe, a presente pesquisa sinalizou o alto índice de rotatividade dos profissionais, por meio do término de contratos temporários ou também por pedidos de desligamento desses contratos antes do prazo, já que existia uma instabilidade em relação à permanência dos psicólogos no serviço, impactando negativamente os trabalhadores, o serviço e, consequentemente, os usuários. Ficou nítido que o distanciamento da gestão política da equipe e a falta de implicação da primeira no que tange à necessidade de os profissionais compreenderem as possibilidades de permanência ou não no serviço geraram, em muitos momentos, estresse e desequilíbrio emocional, influenciando na saúde dos trabalhadores.

A precarização percorreu os elementos desta pesquisa, pois todos os entrevistados trouxeram com muita clareza as falhas das instalações, a falta de recursos, a impossibilidade de atendimento devido à influência do clima nos prédios impossibilitados de receber os usuários, entre outros. Todavia, para as condições precárias de trabalho, os psicólogos utilizaram estratégias individuais e, por vezes, coletivas para dar conta dessas fragilidades e continuar com a sua prática no serviço.

Pode-se afirmar que os participantes davam ao seu sofrimento uma expressão criativa, ao buscar a solução para os impasses e os problemas enfrentados. A construção de processos coletivos de ressignificação do fazer desses psicólogos pode atuar ampliando a riqueza dessa atuação socioprofissional. A Psicodinâmica, de acordo com Dejours (2004), denomina esse processo de mobilização subjetiva, através da qual pode haver a superação e a solução de problemas encontrados diante das contradições do real do trabalho.

Os profissionais trazem que as questões relacionadas à falta de um "olhar para o CREAS" era o que tornava os dias de trabalho difíceis, referindo-se diretamente à gestão ineficaz em que estavam submetidos. Traesel e Merlo (2016) apresentam uma pertinente reflexão sobra a precarização, afirmando que ela tem imposto prejuízos aos trabalhadores, em especial no setor público, uma vez que os modos de gestão advindos do setor privado têm devastado o fazer público, lesando a sociedade no que se refere à garantia de seus direitos. Os contratos temporários vêm ao encontro dessa lógica de exploração e desconsideração dos resultados sociais, privilegiando apenas os resultados econômicos.

A presente pesquisa buscou elucidar a experiência de trabalho temporário de psicólogos que atuaram no CREAS e, com isso, fomentar discussões tanto no meio acadêmico quanto em outros contextos sociais, voltando o olhar para as fragilidades desse ramo de trabalho. Assim, estudar a interlocução entre a Assistência Social e a terceirização, à luz da Teoria Psicodinâmica, tem sido cada vez mais necessária, tamanho os riscos que esses dois elementos combinados podem repercutir na esfera social.

Martins, Mendes, Antloga e Maia (2017) defendem que as condições precárias de trabalho e a flexibilização dos contratos não podem diminuir a importância desses trabalhadores. Esse valor profissional precisa ser resgatado, primeiramente, dentro da própria categoria profissional. Assim, é preciso abrir espaços de discussão e reflexão, tais como aqueles propostos pela Psicodinâmica do Trabalho (Dejours, 2011).

Esses espaços podem deflagrar a interlocução sobre as condições de trabalho do psicólogo nesse contexto, desnaturalizando essas práticas e a submissão existente, com vistas a construir coletivamente modos de atuação menos penosos e relações de trabalho mais saudáveis e emancipatórias. Ainda que o profissional da Psicologia esteja suscetível às artimanhas e amarras existentes nos processos laborais capitalistas, ele tem papel fundamental para um processo de mudança nesse panorama, no sentido de ter ferramentas de luta contra o processo de alienação do 
trabalhador, cuja formação proporciona instrumentos para combater esse tipo de vínculo de trabalho.

Defende-se que há outras interações possíveis nesse contexto, através da criação de formas coletivas de libertação desses modos de dominação e esfacelamento do fazer psicológico, resgatando o sentido desse trabalho e seu importante papel sociopolítico. É função da Psicologia reunir forças para promover o esclarecimento e a busca pela garantia dos direitos.
Por fim, é possível visualizar algumas limitações do estudo, como a inclusão de psicólogos que já tinham seus contratos finalizados e a investigação somente de uma cidade. Psicólogos atuando em vigência de seus contratos e a inclusão de psicólogos de diferentes regiões do estado poderiam ter fornecido dados complementares ou contrastantes para a compreensão do fenômeno, constituindo-se em planos para os próximos estudos.

\section{Referências}

Amaral, A., Mota, D., \& Alves, G. (Orgs.). (2011). Trabalho e saúde: A precarização do trabalho e a saúde do trabalhador no Século XXI. São Paulo, SP: LTr.

Antunes, R. (2005). Os sentidos do trabalho. São Paulo, SP: Boitempo.

Bardin, L. (2009). Análise de conteúdo. Lisboa: 70.

Brasil. Ministério do Desenvolvimento Social e Combate à Fome. (2005). Norma operacional básica NOB/SUAS. Brasília, DF: Secretaria Nacional de Assistência Social.

Chiavenato, I. (2002). Recursos humanos (7a ed.). São Paulo, SP: Atlas.

Chiavenato, I. (2006). Administração de recursos humanos (6a ed.). São Paulo, SP: Atlas.

Codo, W., Sampaio, J. J. C., \& Hitomi, A. H. (1993). Indivíduo, trabalho e sofrimento: Uma abordagem interdisciplinar. Petrópolis, RS: Vozes.

Conselho Federal de Psicologia - CFP. (2009). Serviço de proteção social a crianças e adolescentes vítimas de violência, abuso e exploração sexual e suas famílias: Referências para a atuação do psicólogo. Brasília, DF: o autor.

Conselho Federal de Psicologia - CFP. (2010). Atuação dos psicólogos no CREAS e outros serviços especiais de acolhida e atendimento domiciliar do SUAS (Relatório descritivo preliminar de pesquisa). Brasília, DF: o autor.

Dejours, C. (1992). A loucura do trabalho: Estudo de psicopatologia do trabalho (5a ed.). São Paulo, SP: Cortez.

Dejours, C. (1994). Psicodinâmica do trabalho: Contribuições da escola dejouriana à análise da relação prazer, sofrimento trabalho. São Paulo, SP: Atlas.

Dejours, C. (1998). Souffrance en France. Paris: Seuil.

Dejours, C. (1999). A banalização da injustiça social. Rio de Janeiro, RJ: Fundação Getúlio Vargas.

Dejours, C. (2004). Subjetividade, trabalho e ação. Revista Produção, 14(3), 27-34. https://doi.org/10.1590/S010365132004000300004

Dejours, C. (2011). Da psicopatologia à psicodinâmica do trabalho. Rio de Janeiro, RJ: Fundação Oswaldo Cruz.

Di Giovanni, G. (2009). As estruturas elementares das políticas públicas. Campinas, SP: Unicamp.

Druck, G., \& Franco, T. (Orgs.). (2007). A perda da razão social do trabalho: Terceirização e precarização. São Paulo, SP: Boitempo.

Ferreira, M. C., \& Mendes, A. M. B. (2003). Trabalho e risco de adoecimento: O caso dos auditores-fiscais da previdência social brasileira. Brasília, DF: LPA.

Ferreira M. C., Araújo, J., Almeida, C., \& Mendes, A. M. (2011). Dominação e resistência no contexto trabalho-saúde. São Paulo, SP: Mackenzie.

Fontanella, B. J. B., Ricas, J., \& Turato, E. R. (2008). Amostragem por saturação em pesquisas qualitativas em saúde: Contribuições teóricas. Caderno de Saúde Pública, 24(1), 17-27.https://doi.org/10.1590/S0102-311X2008000100003

Freire, M. L., \& Alberto, M. F. P. (2013). Centro de referência especializada de assistência social: Suporte organizacional para atuação do psicólogo. Cadernos de Psicologia Social e do Trabalho, 16(2), 167-182. 
Grossi, P. K.,Vieira, M. S., Gasparotto, G. P., Coutinho, A. R. C., Barcelos, M. I. N., \& Leite, M. (2013). O trabalho do assistente social no CREAS: Impasses e desafios para a garantia dos direitos. In Pontificia Universidade Católica do Rio Grande do Sul, Anais do Seminário Internacional sobre Políticas Públicas, Intersetorialidade e Família. Porto Alegre, RS: o autor. Recuperado de http://ebooks.pucrs.br/edipucrs/anais/sipinf/edicoes/I/42.pdf

Harvey, D. (1992). Condição pós-moderna: Uma pesquisa sobre as origens da mudança cultural. São Paulo, SP: Loyola.

Job, F. P. P. (2003). Os sentidos do trabalho e a importância da resiliência nas organizações (Tese de doutorado). Fundação Getúlio Vargas, São Paulo, SP, Brasil.

Macedo, J. P., \& Dimenstein, M. (2011). Expansão e interiorização da psicologia: Reorganização do saberes e poderes na atualidade. Psicologia: Ciência e Profissão, 31(2), 296-13. https://doi.org/10.1590/S1414-98932011000200008

Macedo, J. P., Sousa, A. P., Carvalho, D. M., Magalhães, M. A., Souza, F. M. S., \& Dimenstein, M. (2011). O psicólogo brasileiro no SUAS: Quantos somos e onde estamos? Psicologia em Estudo, 16(3), 479-489. https://doi. org/10.1590/S1413-73722011000300015

Martins, J., \& Bicudo, M. A. V. (1994). A pesquisa qualitativa em psicologia: Fundamentos e recursos básicos. São Paulo, SP: Moraes.

Martins, M., Mendes, A. M., Antloga, C. S., \& Maia, M. (2017). A psicodinâmica do reconhecimento no trabalho de informática de terceirizados de uma instituição pública. Revista Brasileira de Medicina do Trabalho, 15(3), 244251. https://doi.org/10.5327/Z1679443520174916

Mendes, A. M. B. (2007). Psicodinâmica do trabalho: Teoria, método e pesquisas. São Paulo, SP: Casa do Psicólogo.

Mendes, A. M. B., \& Morroni, C. F. (2011). Trajetória teórica e pesquisas brasileiras sobre prazer e sofrimento no trabalho. In A. M. Mendes, Á. R. C. Merlo, C. F. Morrone, \& E. Facas (Orgs.), Psicodinâmica e clínica do trabalho: Temas, interfaces e casos brasileiros (pp. 29-52). Curitiba, PR: Juruá.

Merlo, A. R. C., \& Mendes, A. M. B. (2009). Perspectivas do uso da psicodinâmica do trabalho no Brasil: Teoria, pesquisa e ação. Cadernos de Psicologia Sociale do Trabalho, 12(2), 141-156. https://doi.org/10.11606/issn.1981-0490.v12i2p141-156

Merlo, A., Traesel, E. S., \& Baierle, T. C. (2013). Banalização do mal. In F. O. Vieira (Org.), Dicionário crítico de gestão e psicodinâmica do trabalho (pp. 71-76). Curitiba, PR: Juruá.

Paixão, C., \& Lorenço, R., Filho. (2014). Impactos da terceirização no mundo do trabalho: Tempo, espaço e subjetividade. Revista do Tribunal Superior do Trabalho, 80(3), 58-74.

Paz, F. A. R. (2015). A precarização no trabalho do assistente social na política de assistência social. In Universidade Federal do Maranhão, Anais da 7 Jornada internacional de políticas públicas. São Luís, MA: o autor. Recuperado de: http://www.joinpp.ufma.br/jornadas/joinpp2015/pdfs/eixo2/a-precarizacao-no-trabalho-do-assistente-social-na-politica-de-assistencia-social.pdf

Raichelis, R. (2010). Intervenção profissional do assistente social e as condições de trabalho no SUAS. Serviço Social \& Sociedade, (104), 750-772. https://doi.org/10.1590/S0101-66282010000400010

Ribeiro, M. E., \& Guzzo, R. S. L. (2014). Psicologia no sistema único de assistência social (SUAS): Reflexões críticas sobre ações e dilemas profissionais. Pesquisas e Práticas Psicossociais, 9(1), 83-96.

Ramos, M. Z., Bianchessi, D. L. C., Merlo, A. R. C., Poersch, A. L., Veeck, C., \& Heisller, S. Z. (2010). Trabalho, adoecimento e histórias de vida em trabalhadoras da indústria calçadista. Estudos de Psicologia (Natal), 15(2), 207-215. https://doi.org/10.1590/S1413-294X2010000200010

Sennet, R. (2001). A corrosão do caráter: As consequências pessoais do trabalho no novo capitalismo. Rio de Janeiro, RJ: Record.

Stancato, K., \& Zilli, P. T. (2010). Fatores geradores da rotatividade dos profissionais de saúde: Uma revisão da literatura. Revista Administração e Saúde, 12(47), 87-99.

Super, D. E. (1990). Toward making self concept theory operational. In D. Brown, \& L. Brooks (Orgs.), Career choice and development (pp. 197-261). San Francisco, CA: Jossey Bass.

World Health Association - WHO. (1994). Qualitative research for health programmes. Geneva: o autor.

Ximenes, V. M., Paula, L. R. C., \& Barros, J. P. P. (2009). Psicologia comunitária e política de assistência social: Diálogos sobre atuações em comunidades. Psicologia: Ciência e Profissão, 29(4), 686-699. https://doi.org/10.1590/ S1414-98932009000400004 
Yamamoto, O. H., \& Paiva, I. L. (2010). Formação e prática comunitária do psicólogo no âmbito do "terceiro setor". Estudos de Psicologia (Natal), 15(2), 153-160. https://doi.org/10.1590/S1413-294X2010000200004

\section{Cassiele Gomes Pauli}

Mestra em Psicologia - Universidade Federal de Santa Maria (UFSM), Santa Maria - RS. Brasil.

E-mail: cassipauli@hotmail.com

$$
\text { (iD) https://orcid.org/0000-0003-0168-999X }
$$

\section{Elisete Soares Traesel}

Doutora em Psicologia Social e Institucional - Universidade Federal do Rio Grande do Sul (UFRGS), Porto Alegre RS. Brasil. Docente do Departamento de Psicologia da Universidade Federal Fluminense (UFF).

E-mail: etraesel@id.uff.br

(iD) https://orcid.org/0000-0003-0877-7087

\section{Aline Cardoso Siqueira}

Pós-doutoranda do PPG em Psicologia da UFSCar. Docente do Departamento de Psicologia da Universidade Federal de Santa Maria (UFSM), Santa Maria - RS. Brasil.

E-mail: alinecsiq@gmail.com

(iD) https:// orcid.org/0000-0003-1430-9722

Endereço para envio de correspondência:

Av. Roraima, 1000, 74B, $2^{\circ}$ andar, sala 3205 Cidade Universitária. Bairro Camobi. CEP: 97015-900.

Santa Maria - RS. Brasil.

Recebido 23/11/2017

Reformulado 06/06/2018-24/08/2018

Aceito 27/09/2018

Received 11/23/2017

Reformulated 06/06/2018-08/24/2018

Approved 09/27/2018

Recibido 23/11/2017

Reformulado 06/06/2018-24/08/2018

Aceptado 27/09/2018

Como citar: Pauli, C. G., Traesel, E. S., Siqueira, A. C. (2019). A Precarização do Trabalho dos Psicólogos Temporários no CREAS. Psicologia: Ciência e Profissão, 39, 1-13. https:// doi.org/10.1590/1982-3703003188301

How to cite: Pauli, C. G., Traesel, E. S., Siqueira, A. C. (2019). Precarious Work Conditions of Psychologists on CREAS. Psicologia: Ciência e Profissão, 39, 1-13. https://doi.org/10.1590/1982-3703003188301

Cómo citar: Pauli, C. G., Traesel, E. S., Siqueira, A. C. (2019). La Precariedad Del Trabajo de los Psicólogos Temporales en el CREAS. Psicologia: Ciência e Profissão, 39, 1-13. https://doi.org/10.1590/1982-3703003188301 